\title{
CoMposiçÃo QUímiCA E BROMATOLÓGICA DE Egeria densa, Egeria najas E Ceratophyllum demersum ${ }^{1}$
}

\author{
Chemical and Bromatological Composition of Egeria densa, Egeria najas and \\ Ceratophyllum demersum
}

\author{
CORREAA, M.R. ${ }^{2}$, VELINI, E.D. ${ }^{3}$ e ARRUDA, D.P. ${ }^{4}$
}

\begin{abstract}
RESUMO - O objetivo deste trabalho foi avaliar a composição química e bromatológica de três espécies de plantas aquáticas imersas provenientes de operações de controle mecânico, para, posteriormente, determinar a melhor estratégia para descarte e/ou aproveitamento da biomassa coletada nestas operações. O estudo foi realizado no verão e inverno de 2001, sendo realizadas coletas em nove pontos da porção Tietê do reservatório de Jupiá. As amostras foram desidratadas, moídas e encaminhadas aos laboratórios para análise. Para as três espécies, a maior concentração dos elementos analisados foi observada em plantas coletadas durante o verão, com certo declínio nas concentrações nas plantas coletadas no inverno. C. demersum mostrou melhor constituição bromatológica, com índices superiores de proteína bruta, minerais e digestibilidade.
\end{abstract}

Palavras-chave: controle mecânico, descarte, macrófitas aquáticas.

ABSTRACT - The purpose of this work was to evaluate the chemical and bromatological composition of three submerged aquatic plant species originated from mechanical control operations, to later determine the best strategy to discard and/or use the biomass harvested during the mechanical control operations. This study was carried out in the summer and winter of 2001, with the plants being harvested at nine points on Tietê River of the Jupia reservoir. Samples were dried, milled and sent for analysis. Among the three species, the highest concentration of the analyzed elements was observed in plants harvested during the summer with a decrease in concentration being observed in plants harvested in the winter. C. demersum showed the best bromatological concentration with higher rates of crude protein, minerals and digestibility.

Key words: mechanical control, discard, aquatic macrophytes.

\section{INTRODUÇÃO}

No Brasil, em razão da extensa rede hidrográfica, há elevado número de reservatórios, importantes em se tratando do fornecimento de água para dar suporte aos sistemas de produção agrícola e industrial, consumo humano, recreação, navegação, irrigação, pesca e geração de energia (Velini, 2000). A acentuada demanda de energia nos centros urbanos e complexos industriais, exigindo sistemas constantes de fornecimento de água, justifica a construção desse número elevado de reservatórios e represas (Moraes, 1999).

Recebido para publicação em 11.12.2003 e na forma revisada em 28.3.2003.

2 Eng.-Agr., aluno de pós-graduação, Dep. Produção Vegetal/Agricultura da Faculdade de Ciências Agronômicas - FCA-UNESP, Caixa Postal 237, 18603-970 Botucatu-SP, <mrcorrea@ fca.unesp.br>; ${ }^{3}$ Prof. Dr., Dep. Produção Vegetal/Agricultura - FCAUNESP. ${ }^{4}$ Aluno do curso de Química, Universidade do Sagrado Coração, Bauru-SP. 
A construção de barragens, transformando rios em grandes reservatórios, associada ao carregamento de nutrientes para o leito dos rios através do aporte de despejos domésticos e industriais, tem levado a uma condição de desequilíbrio no sistema hídrico, caracterizado pela grande disponibilidade de nutrientes (Valente et al., 1997; Velini, 2000). Esse processo é denominado eutrofização, que acarreta aumento da produtividade biológica e ocasiona problemas que vão desde a estética até o comprometimento da possível utilização da água para recreação e/ou abastecimento, devido à grande concentração de algas e vegetação aquática (Pinto \& Cavalcanti, s.d.).

Grande parte dos reservatórios da Região Sudeste é colonizada por macrófitas aquáticas, apresentando problemas operacionais e de usos múltiplos em decorrência do desenvolvimento excessivo da vegetação aquática (Thomaz \& Bini, 1998). Principe et al. (1997) e Velini (2000) afirmam que várias empresas geradoras de energia vêm tendo grandes prejuízos em razão da presença de plantas aquáticas, o que ocasiona grandes transtornos à operação das usinas.

A vegetação aquática passa a ser encarada como daninha quando seu crescimento acentuado causa problemas para a utilização dos ecossistemas, surgindo a partir desse momento a necessidade de aplicação de métodos de controle ou manejo.

O controle mecânico utilizando embarcações apropriadas, visando a retirada da biomassa do corpo hídrico, é uma das alternativas a serem consideradas. Embora este método apresente algumas vantagens, como ação de modo pontual nas áreas infestadas e não-contaminação do ambiente com compostos químicos e tóxicos, existe a preocupação em relação ao material coletado a ser descartado, haja vista a grande quantidade de biomassa envolvida nesse processo.

Dessa forma o objetivo deste trabalho foi avaliar a composição química e bromatológica de Egeria densa, Egeria najas e Ceratophyllum demersum, principais plantas aquáticas problemáticas do reservatório de Jupiá, visando o estabelecimento de programas de controle mecânico destas, com a utilização do material coletado para fertilização do solo e alimentação animal. Os resultados também podem auxiliar o estabelecimento de programas biológicos de controle, pois permitem avaliar a aptidão das três espécies para suportar o crescimento de herbívoros.

\section{MATERIAL E MÉTODOS}

Amostras das três espécies foram coletadas em duas épocas do ano, verão e inverno, em vários pontos da porção Tietê do reservatório da usina hidrelétrica de Jupiá, envolvendo quatro lagoas marginais e o leito do rio em questão, num trecho correspondente do canal de eclusagem da Usina de Três Irmãos até a confluência com o rio Paraná, no município de Itapura. As plantas foram coletadas com auxílio de um gancho, em bancos homogêneos de colonização, sendo colocadas em sacos plásticos com água, mantendo-se a umidade das plantas durante o transporte.

Em laboratório, as amostras foram separadas por espécie, sendo lavadas em água, para remoção do material contaminante aderido durante as coletas. Em seguida, após breve secagem, para retirada de excesso de água, as plantas foram acondicionadas em sacos de papel e colocadas em estufa de circulação forçada de ar a uma temperatura de $60{ }^{\circ} \mathrm{C}$ por um período de sete dias; posteriormente, elas foram moídas em micromoinho e encaminhadas aos laboratórios, para análise dos nutrientes nelas presentes.

A determinação dos elementos químicos foi realizada no laboratório de relação solo-planta do Departamento de Produção Vegetal, Setor Agricultura, da FCA-Unesp/Botucatu. Para determinação dos teores dos elementos, o material foi digerido com uma mistura de ácido nítrico e ácido perclórico, e outra com solução digestora apenas para nitrogênio, seguindo metodologia sugerida por Malavolta et al. (1989). Na determinação do elemento carbono utilizou-se a metodologia proposta por Tedesco et al. (1985), com uma digestão diferente da utilizada para os outros elementos.

As amostras digeridas foram submetidas à espectrometria de plasma, para determinação direta das concentrações de $\mathrm{K}, \mathrm{Ca}, \mathrm{Mg}, \mathrm{Al}, \mathrm{Co}$, $\mathrm{Cu}, \mathrm{Fe}, \mathrm{Si}$ e $\mathrm{Zn}$. As concentrações de P e S foram obtidas através de espectrometria digital 
com injeção de fluxo, e os teores de $\mathrm{N}$ e C, por meio de titulações.

A análise da bromatologia das plantas aquáticas foi feita no Laboratório de Nutrição Animal do Departamento de Zootecnia da Faculdade de Medicina Veterinária e Zootecnia, Unesp/Botucatu, utilizando-se métodos de rotina, com a finalidade de conhecer todos os componentes existentes nas plantas, de forma a proporcionar a melhor maneira de utilização da biomassa descartada.

Utilizou-se o programa SAS for Windows (SAS, 1996) para determinar as diferenças nas concentrações dos elementos químicos presentes nas macrófitas aquáticas, considerandose os meses de estudo, as épocas de amostragem e a espécie de planta. Os resultados foram submetidos à análise de variância, comparando-se as médias dos tratamentos com auxílio do teste "t" a 10\% de probabilidade.

\section{RESULTADOS E DISCUSSÃO}

Os teores de carbono não diferiram estatisticamente $(p<0,1)$ entre as espécies de plantas amostradas no verão; $E$. najas apresentou o maior teor médio deste elemento (Tabela 1). O mesmo comportamento pode ser observado nas amostragens realizadas no inverno, porém neste período $E$. densa apresentou o maior conteúdo deste elemento (Tabela 2). Não foi observada variação sazonal significativa para este elemento nas três espécies de plantas analisadas (Tabela 3).

Os valores médios de nitrogênio encontrados nas plantas amostradas nos períodos de verão e inverno (Tabelas 1 e 2 , respectivamente) mostraram-se semelhantes para as três espécies, sem que fosse observada diferença estatisticamente significativa entre elas, com a espécie $C$. demersum apresentando valores superiores em ambas as estações do ano. Esses valores estão abaixo dos observados por Bitar (1998), que encontrou concentrações médias de $34,9 \mathrm{~g} \mathrm{~N} \mathrm{~kg}^{-1}$ em Pistia stratiotes, e por Greenway (1997) em plantas de Monochoria cyanea (35 $\mathrm{mg} \mathrm{N} \mathrm{g}^{-1}$ ), em lagos de Queensland.

$\mathrm{O}$ conhecimento sobre a relação $\mathrm{C} / \mathrm{N}$ e a decomposição dos resíduos orgânicos é importante no manejo de restos culturais no solo, para futura nutrição de plantas cultivadas. Neste trabalho, essa relação é importante, pelo fato de que o processo de decomposição da biomassa é acelerado, otimizando o uso de

Tabela 1 - Teores médios de nutrientes em plantas aquáticas imersas presentes no reservatório de Jupiá. Coleta realizada em 8 de janeiro de 2001, em nove locais ao longo do rio Tietê. Botucatu-SP, 2001

\begin{tabular}{|c|c|c|c|c|c|c|c|c|c|c|c|c|c|}
\hline \multirow{2}{*}{ Espécie } & $\%$ & \multicolumn{6}{|c|}{$\mathrm{g} \mathrm{kg}^{-1}$ de Matéria Seca } & \multicolumn{6}{|c|}{$\mathrm{mg} \mathrm{kg}^{-1}$ de Matéria Seca } \\
\hline & $\mathrm{C}$ & $\mathrm{N}$ & $\mathrm{P}$ & $\mathrm{K}$ & $\mathrm{Ca}$ & $S$ & $\mathrm{Mg}$ & $\mathrm{Al}$ & Co & $\mathrm{Cu}$ & $\mathrm{Fe}$ & $\mathrm{Si}$ & $\mathrm{Zn}$ \\
\hline Egeriad & $34,4 \mathrm{a}$ & $26,0 \mathrm{a}$ & $1,9 \mathrm{a}$ & $15,6 \mathrm{~b}$ & $27,6 \mathrm{a}$ & $3,2 \mathrm{a}$ & $4,9 \mathrm{c}$ & $5,3 \mathrm{a}$ & $6,5 \mathrm{~b}$ & $20,7 \mathrm{a}$ & $2537,0 \mathrm{a}$ & $23,8 \mathrm{a}$ & 102,9 a \\
\hline Egeria najas & $34,6 \mathrm{a}$ & $24,5 \mathrm{a}$ & $2,2 \mathrm{a}$ & $14,7 \mathrm{~b}$ & $25,5 \mathrm{a}$ & $2,9 \mathrm{a}$ & $9,3 \mathrm{~b}$ & $1295,5 \mathrm{a}$ & $4,1 \mathrm{~b}$ & $18,0 \mathrm{a}$ & $2668,0 \mathrm{a}$ & $23,0 \mathrm{a}$ & $130,5 \mathrm{a}$ \\
\hline C. demersum & $32,9 \mathrm{a}$ & $28,9 \mathrm{a}$ & $1,0 \mathrm{a}$ & $22,2 \mathrm{a}$ & $24,3 \mathrm{a}$ & $3,4 \mathrm{a}$ & $19,6 \mathrm{a}$ & $1881,4 \mathrm{a}$ & $11,4 \mathrm{a}$ & $24,2 \mathrm{a}$ & $3456,8 \mathrm{a}$ & $23,2 \mathrm{a}$ & $149,0 \mathrm{a}$ \\
\hline $\mathrm{CV}$ & 8,199 & 19,197 & 28,998 & 21,416 & 38,277 & 21,674 & 27,484 & 81,170 & 63,425 & 40,136 & $\overline{65,540}$ & 50,859 & 53,289 \\
\hline $\mathrm{F}$ & $0,97^{\mathrm{ns}}$ & $1,56^{\mathrm{ns}}$ & $0,87^{\text {ns }}$ & $10,10^{*}$ & $0,24^{\mathrm{ns}}$ & $0,70^{\mathrm{ns}}$ & $51,03^{*}$ & $0,65^{\mathrm{ns}}$ & $4,88^{*}$ & $0,97^{\mathrm{ns}}$ & $0,60^{\text {ns }}$ & $0,01^{\mathrm{ns}}$ & $1,05^{\mathrm{ns}}$ \\
\hline
\end{tabular}

Médias seguidas de mesma letra, por espécie, nas colunas, não diferem estatisticamente a $10 \%$ de probabilidade.

Tabela 2 - Teores médios de nutrientes em plantas aquáticas imersas presentes no reservatório de Jupiá. Coleta realizada em 24 de julho de 2001, em nove locais ao longo do rio Tietê. Botucatu-SP, 2001

\begin{tabular}{|c|c|c|c|c|c|c|c|c|c|c|c|c|c|}
\hline \multirow{2}{*}{ Espécie } & $\%$ & \multicolumn{6}{|c|}{$\mathrm{g} \mathrm{kg}^{-1}$ de Matéria Seca } & \multicolumn{6}{|c|}{$\mathrm{mg} \mathrm{kg}^{-1}$ de Matéria Seca } \\
\hline & $\mathrm{C}$ & $\mathrm{N}$ & $\mathrm{P}$ & $\mathrm{K}$ & $\mathrm{Ca}$ & $S$ & $\mathrm{Mg}$ & $\mathrm{Al}$ & Co & $\mathrm{Cu}$ & $\mathrm{Fe}$ & $\mathrm{Si}$ & $\mathrm{Zn}$ \\
\hline Egeria densa & $34,5 \mathrm{a}$ & $25,9 \mathrm{a}$ & $1,5 \mathrm{a}$ & $17,5 \mathrm{a}$ & $17,3 \mathrm{a}$ & $2,5 \mathrm{a}$ & $3,6 \mathrm{c}$ & $1330,3 \mathrm{a}$ & $4,1 \mathrm{ab}$ & $5,9 \mathrm{a}$ & $2154,9 \mathrm{a}$ & $20,5 \mathrm{a}$ & $20,7 \mathrm{a}$ \\
\hline Egeria najas & $32,4 \mathrm{a}$ & $25,7 \mathrm{a}$ & $1,8 \mathrm{a}$ & $18,6 \mathrm{a}$ & $16,5 \mathrm{ab}$ & $3,2 \mathrm{a}$ & $7,6 \mathrm{~b}$ & $1794,0 \mathrm{a}$ & $3,3 \mathrm{~b}$ & $5,7 \mathrm{a}$ & $2958,5 \mathrm{a}$ & $32,1 \mathrm{a}$ & $20,2 \mathrm{a}$ \\
\hline C. demersum & $33,8 \mathrm{a}$ & $28,6 \mathrm{a}$ & $1,9 \mathrm{a}$ & $9,6 \mathrm{~b}$ & $11,8 \mathrm{~b}$ & $2,5 \mathrm{a}$ & $9,8 \mathrm{a}$ & $2255,0 \mathrm{a}$ & $6,0 \mathrm{a}$ & $4,6 \mathrm{a}$ & $3526,2 \mathrm{a}$ & $28,3 \mathrm{a}$ & $23,1 \mathrm{a}$ \\
\hline $\mathrm{CV}(\%)$ & 9,683 & 25,252 & 34,006 & $\overline{48,776}$ & 37,144 & 37,163 & 35,801 & 108,643 & 53,869 & 69,004 & 89,684 & 110,768 & 50,827 \\
\hline$F_{F}$ & $0,87^{\mathrm{ns}}$ & $1,38^{\mathrm{ns}}$ & $1,34^{\mathrm{ns}}$ & $3,87^{*}$ & $2,42^{\mathrm{ns}}$ & $1,46^{\mathrm{ns}}$ & $14,32^{*}$ & $0,51^{\mathrm{ns}}$ & $2,85^{*}$ & $0,27^{\mathrm{ns}}$ & $0,64^{\mathrm{ns}}$ & $0,12^{\mathrm{ns}}$ & $0,18^{\text {ns }}$ \\
\hline
\end{tabular}

Médias seguidas de mesma letra, por espécie, nas colunas, não diferem estatisticamente a $10 \%$ de probabilidade. 
Tabela 3 - Teores médios de nutrientes em plantas aquáticas imersas presentes no reservatório de Jupiá. Coleta realizada em 24 de julho de 2001, em nove locais ao longo do rio Tietê. Botucatu-SP, 2001

\begin{tabular}{|c|c|c|c|c|c|c|c|c|c|c|c|c|c|}
\hline \multirow{2}{*}{ Espécie } & $\%$ & \multicolumn{6}{|c|}{$\mathrm{g} \mathrm{kg}^{-1}$ de Matéria Seca } & \multicolumn{6}{|c|}{$\mathrm{mg} \mathrm{kg}^{-1}$ de Matéria Seca } \\
\hline & $\mathrm{C}$ & $\mathrm{N}$ & $\mathrm{P}$ & $\mathrm{K}$ & $\mathrm{Ca}$ & $S$ & $\mathrm{Mg}$ & $\mathrm{Al}$ & Co & $\mathrm{Cu}$ & $\mathrm{Fe}$ & $\mathrm{Si}$ & $\mathrm{Zn}$ \\
\hline Egeria densa (verão) & 34,4 a & $26,0 \mathrm{a}$ & $1,9 \mathrm{a}$ & $15,6 \mathrm{a}$ & $27,6 \mathrm{a}$ & $3,2 \mathrm{a}$ & $4,9 \mathrm{a}$ & $1305,3 \mathrm{a}$ & $6,5 \mathrm{a}$ & $20,7 \mathrm{a}$ & $2537,0 \mathrm{a}$ & $23,8 \mathrm{a}$ & $102,9 \mathrm{a}$ \\
\hline & $34,5 \mathrm{a}$ & $25,9 \mathrm{a}$ & $1,5 \mathrm{~b}$ & $17,5 \mathrm{a}$ & $17,3 \mathrm{~b}$ & $2,5 \mathrm{a}$ & & $1330,3 \mathrm{a}$ & $4,1 \mathrm{a}$ & $5,9 \mathrm{~b}$ & $2154,9 \mathrm{a}$ & $20,5 \mathrm{a}$ & $20,7 \mathrm{~b}$ \\
\hline $\mathrm{CV}(\%)$ & 8,248 & 19,818 & 27,909 & 37,295 & 38,598 & 34,794 & 22,354 & 77,357 & 75,717 & 43,632 & 65,205 & 52,377 & 70,614 \\
\hline $\mathrm{F}$ & $0,002^{\mathrm{ns}}$ & $0,002^{\text {ns }}$ & $3,73^{*}$ & $0,44^{\text {ns }}$ & $6,37^{*}$ & $2,10^{\mathrm{ns}}$ & $9,39^{*}$ & $0,002^{\mathrm{ns}}$ & $1,55^{\mathrm{ns}}$ & $29,33^{*}$ & $0,28^{\text {ns }}$ & $0,17^{\mathrm{ns}}$ & $15,97^{*}$ \\
\hline Egeria najas (verão) & 34,6 a & $24,5 \mathrm{a}$ & $2,2 \mathrm{a}$ & $14,7 \mathrm{~b}$ & $25,5 \mathrm{a}$ & $2,9 \mathrm{a}$ & $9,3 \mathrm{a}$ & $1295,5 \mathrm{a}$ & $4,1 \mathrm{a}$ & $18,0 \mathrm{a}$ & $2668,0 \mathrm{a}$ & $23,0 \mathrm{a}$ & $130,5 \mathrm{a}$ \\
\hline Egeria najas (inverno) & $32,4 \mathrm{a}$ & $25,7 \mathrm{a}$ & $1,8 \mathrm{a}$ & $18,6 \mathrm{a}$ & $16,5 \mathrm{~b}$ & $3,2 \mathrm{a}$ & $7,6 \mathrm{a}$ & $1794,0 \mathrm{a}$ & $3,3 \mathrm{a}$ & $5,7 \mathrm{~b}$ & $2958,5 \mathrm{a}$ & $32,1 \mathrm{a}$ & $20,2 \mathrm{~b}$ \\
\hline $\mathrm{CV}(\%)$ & 10,318 & 12,837 & 22,927 & 35,516 & 22,852 & 28,691 & 22,508 & 70,886 & 54,842 & 68,388 & 67,127 & 40,259 & 73,039 \\
\hline $\mathrm{F}$ & $1,54^{\mathrm{ns}}$ & $0,57^{\mathrm{ns}}$ & $1,76^{\mathrm{ns}}$ & $1,63^{\mathrm{ns}}$ & $13,53^{*}$ & $0,35^{\mathrm{ns}}$ & $2,78^{\mathrm{ns}}$ & $0,76^{\mathrm{ns}}$ & $0,69^{\mathrm{ns}}$ & $8,10^{*}$ & $0,09^{\text {ns }}$ & $1,63^{\text {ns }}$ & $16,57^{*}$ \\
\hline C. demersum (verão) & $32,9 \mathrm{a}$ & $28,9 \mathrm{a}$ & $1,0 \mathrm{a}$ & $22,2 \mathrm{a}$ & $24,3 \mathrm{a}$ & $3,4 \mathrm{a}$ & 19,6 a & $1881,4 \mathrm{a}$ & $11,4 \mathrm{a}$ & $24,2 \mathrm{a}$ & $3456,8 \mathrm{a}$ & $23,2 \mathrm{a}$ & $149,0 \mathrm{a}$ \\
\hline C. demersum (inverno) & $33,8 \mathrm{a}$ & $28,6 \mathrm{a}$ & $1,9 \mathrm{a}$ & $9,6 \mathrm{~b}$ & $11,8 \mathrm{~b}$ & $2,5 \mathrm{~b}$ & $9,8 \mathrm{~b}$ & $2255,0 \mathrm{a}$ & $6,0 \mathrm{~b}$ & $4,6 \mathrm{~b}$ & $3526,2 \mathrm{a}$ & $28,3 \mathrm{a}$ & $23,1 \mathrm{~b}$ \\
\hline $\mathrm{CV}(\%)$ & 8,539 & 17,334 & 31,565 & 34,227 & 51,545 & 23,978 & 29,473 & 113,250 & 52,690 & 39,353 & 87,322 & 105,107 & 56,420 \\
\hline F & $0,41^{\mathrm{ns}}$ & $0,01^{\mathrm{ns}}$ & $0,32^{\mathrm{ns}}$ & $24,09^{*}$ & $8,06^{*}$ & $7,54^{*}$ & $23,06^{*}$ & $0,11^{\mathrm{ns}}$ & $6,27^{*}$ & $48,85^{*}$ & $0,002^{\text {ns }}$ & $0,14^{\mathrm{ns}}$ & $30,22^{*}$ \\
\hline
\end{tabular}

Médias seguidas de mesma letra, por espécie, nas colunas, não diferem estatisticamente a $10 \%$ de probabilidade.

áreas de descarte. Dessa forma, a espécie C. demersum apresentou menor relação $\mathrm{C} / \mathrm{N}$ em ambas as amostragens (11,39 e 11,79, para verão e inverno, respectivamente), valores estes abaixo dos observados por Cooplantio (2001) nas espécies de nabo forrageiro (16) e tremoço (18), usadas como plantas de cobertura em sistemas de plantio direto. No entanto, os resultados indicam que a biomassa aquática a ser descartada poderá ter uma rápida degradação. Este fato pode ser considerado positivo, visto que a rápida liberação de nutrientes para o solo poderá suprir uma provável cultura na área.

O maior conteúdo de fósforo, para plantas amostradas no verão, foi observado na espécie E. najas. Embora tenha apresentado valor médio 2,10 vezes superior ao de C. demersum, não foi observada diferença significativa entre as espécies (Tabela 1). Entretanto, esse valor foi duas vezes superior ao observado por Moraes (1999) em estruturas submersas de $P$. stratiotes e inferior ao encontrado por Greenway (1997) em C. demersum. Nas plantas amostradas no inverno (Tabela 2) não houve variação significativa entre as espécies, com C. demersum e E. najas apresentando concentrações superiores.

A espécie que apresentou maior concentração de potássio, em amostragens feitas no verão, foi C. demersum (Tabela 1), sendo significativamente superior à das demais espécies analisadas. Entretanto, nas coletas do inverno, esta espécie mostrou declínio de 56\% em sua concentração, sendo estatisticamente inferior às espécies de Egeria (Tabela 2) e variando significativamente entre uma época de amostragem e outra (Tabela 3). Os valores médios observados em $E$. densa estão de acordo com Hoyer et al. (1996) que encontraram concentração média em torno de $16 \mathrm{~g} \mathrm{~kg}^{-1}$ nesta espécie.

Quanto ao cálcio, não foi observada diferença estatística entre as espécies nas amostragens feitas durante o verão. Entretanto, nas coletas do período de inverno, o teor observado em $E$. densa foi significativamente superior ao de $C$. demersum; E. najas, com valores intermediários, não diferiu das demais espécies avaliadas (Tabela 2). Variação sazonal significativa foi observada para as três espécies (Tabela 3), com todas elas apresentando menor conteúdo deste elemento nas plantas amostradas no período de inverno. Moraes (1999) obteve resultados semelhantes em $P$. stratiotes, porém inferiores aos observados em Eichornnia crassipes.

A espécie que mostrou maior concentração de enxofre em amostragens realizadas durante o verão foi $C$. demersum, sem que houvesse diferença estatística entre as espécies (Tabela 1). Nas plantas coletadas no inverno, os maiores teores deste elemento, também sem diferença significativa, foram observados em $E$. najas (Tabela 2). Esses valores foram 2,5 vezes inferiores aos observados em E. crassipes por Moraes (1999), em períodos de amostragem semelhantes. Variação sazonal significativa 
(Tabela 3) foi observada somente para a espécie C. demersum, a qual apresentou redução de $27 \%$ no conteúdo de $\mathrm{S}$ em plantas amostradas no inverno, em relação ao verão.

As maiores concentrações de magnésio foram observadas em $C$. demersum, sendo significativamente superiores às encontradas nas espécies de Egeria, tanto em amostragens realizadas no verão como no inverno (Tabelas 1 e 2). No entanto, houve decréscimo acentuado, com diferença significativa, em sua concentração em plantas amostradas no inverno (Tabela 3). Esses valores foram superiores aos observados por Hoyer et al. (1993), como 10,3 e 7,4 $\mathrm{mg} \mathrm{L}^{-1}$, para E. densa e C. demersum, respectivamente.

Os teores médios de alumínio apresentados pelas macrófitas aquáticas analisadas não apresentaram diferença significativa nas amostragens realizadas no período de verão (Tabela 1), com C. demersum apresentando teores médios superiores aos das demais espécies. Nas amostragens do período de inverno (Tabela 2) as espécies mostraram maior acúmulo de $\mathrm{Al}$, quando comparadas às plantas amostradas no verão, com C. demersum apresentando concentração $70 \%$ superior à de E. densa neste período. Mesmo com esse acréscimo nas concentrações, não pôde ser observada variação significativa entre uma amostragem e outra para as três espécies (Tabela 3).

A concentração de cobalto encontrada em C. demersum foi 2,75 vezes maior que a observada na espécie $E$. najas, em amostragens feitas no verão (Tabela 1), sendo significativamente superior à verificada nas espécies de Egeria. Entretanto, nas plantas coletadas no inverno ocorreu queda em sua concentração, diferindo estatisticamente somente para a espécie E. najas, que obteve menor concentração média (Tabela 2). A diferença na concentração de Co em plantas amostradas no verão ou no inverno somente foi observada em C. demersum, com decréscimo de 50\% nas plantas coletadas no inverno.

A maior concentração de cobre nas plantas foi observada nas amostragens do período de verão, com $C$. demersum apresentando maior concentração deste elemento, porém não diferindo significativamente das demais espécies aqui analisadas. Foi observado decréscimo médio de $80 \%$ nas concentrações das três espécies, nas plantas coletadas no inverno em relação às coletadas no verão, sendo essa variação sazonal significativa (Tabela 3 ). Tal fato também pôde ser observado para o elemento zinco, onde, em plantas amostradas no verão, foram encontrados os maiores teores deste elemento. Moraes (1999) observou valores superiores de $\mathrm{Zn}$ nas estruturas submersas de $P$. stratiotes e E. crassipes, com média de 379 e 347 ppm, respectivamente.

A espécie E. densa apresentou menor teor médio de ferro em plantas coletadas durante o verão, e C. demersum mostrou o maior conteúdo deste elemento, sem que fosse observada diferença significativa entre as três espécies de plantas analisadas. A mesma tendência foi observada no inverno - somente $E$. najas apresentou aumento na concentração deste elemento em relação às plantas coletadas no verão (Tabela 3). Embora houvesse decréscimo nos teores deste elemento em algumas espécies, não foi observada diferença significativa entre plantas amostradas no verão e inverno. Moraes (1999) observou redução de aproximadamente $64 \%$ nos teores deste elemento em estruturas submersas de $P$. stratiotes, em períodos de amostragem semelhantes.

O maior teor médio de silício, em plantas amostradas no verão, foi observado em $E$. densa, porém não diferindo estatisticamente das demais espécies (Tabela 1). Nas coletas de inverno, foi $E$. najas a espécie que apresentou maior conteúdo deste elemento em suas estruturas, não sendo significativamente diferente das demais espécies (Tabela 2). Variação sazonal significativa não foi observada (Tabela 3): E. densa apresentou ligeiro declínio na concentração de Si em plantas amostradas no inverno, enquanto para as demais espécies houve incremento nas concentrações.

C. demersum mostrou-se mais protéica e rica em minerais que as demais espécies de plantas, em ambas as amostragens (Tabelas 4 e 5). E. najas apresentou menor palatabilidade que as outras espécies, por possuir maior teor de fibra bruta, com aumento do conteúdo nas plantas coletadas no verão, sendo observada diferença significativa para este parâmetro nesta espécie (Tabela 6). 
Tabela 4 - Composição bromatológica média de plantas aquáticas presentes no reservatório de Jupiá. Coleta realizada em 8 de janeiro de 2001. Botucatu-SP, 2001

\begin{tabular}{|c|c|c|c|c|c|c|}
\hline \multirow{2}{*}{ Espécie } & \multicolumn{6}{|c|}{$\%$ na Matéria Seca } \\
\hline & PB & $\mathrm{EE}$ & MIN & FB & ENN & NDT \\
\hline Egeria densa & $15,8 \mathrm{a}$ & $2,3 \mathrm{a}$ & $13,0 \mathrm{~b}$ & $17,0 \mathrm{~b}$ & $50,6 \mathrm{a}$ & $65,4 \mathrm{a}$ \\
\hline Egeria najas & $15,6 \mathrm{a}$ & $2,3 \mathrm{a}$ & $15,0 \mathrm{~b}$ & $19,7 \mathrm{a}$ & $47,4 \mathrm{ab}$ & $63,4 \mathrm{ab}$ \\
\hline C. demersum & $16,8 \mathrm{a}$ & $1,9 \mathrm{~b}$ & $18,6 \mathrm{a}$ & $18,3 \mathrm{ab}$ & $44,3 \mathrm{~b}$ & $62,0 \mathrm{~b}$ \\
\hline $\mathrm{CV}(\%)$ & 24,954 & 19,006 & 16,111 & 16,841 & 14,234 & 4,239 \\
\hline $\mathrm{F}$ & $0,21^{\mathrm{ns}}$ & $2,49^{\mathrm{ns}}$ & $11,66^{*}$ & $1,56^{\mathrm{ns}}$ & $1,98^{\mathrm{ns}}$ & $3,67^{*}$ \\
\hline
\end{tabular}

Valores seguidos de mesma letra, nas colunas, não diferem entre si a $10 \%$ de probabilidade.

Tabela 5 - Composição bromatológica média de plantas aquáticas presentes no reservatório de Jupiá. Coleta realizada em 24 de julho de 2001. Botucatu-SP, 2001

\begin{tabular}{|l|c|c|c|c|c|c|}
\hline \multirow{2}{*}{ Espécie } & \multicolumn{6}{|c|}{ \% na Matéria Seca } \\
\cline { 2 - 7 } & PB & EE & MIN & FB & ENN & NDT \\
\hline Egeria densa & $16,0 \mathrm{a}$ & $2,6 \mathrm{a}$ & $14,6 \mathrm{~b}$ & $15,5 \mathrm{~b}$ & $46,0 \mathrm{~b}$ & $63,3 \mathrm{~b}$ \\
Egeria najas & $16,0 \mathrm{a}$ & $2,8 \mathrm{a}$ & $14,2 \mathrm{~b}$ & $17,3 \mathrm{a}$ & $46,6 \mathrm{~b}$ & $64,2 \mathrm{ab}$ \\
C. demersum & $17,4 \mathrm{a}$ & $2,6 \mathrm{a}$ & $18,7 \mathrm{a}$ & $16,1 \mathrm{ab}$ & $54,2 \mathrm{a}$ & $66,2 \mathrm{a}$ \\
\hline CV $(\%)$ & 14,137 & 24,163 & 17,552 & 10,271 & 8,930 & 4,625 \\
F & $1,04^{\mathrm{ns}}$ & $0,39^{\mathrm{ns}}$ & $6,81^{*}$ & $2,70^{*}$ & $7,49^{*}$ & $2,16^{\mathrm{ns}}$ \\
\hline
\end{tabular}

Valores seguidos de mesma letra, nas colunas, não diferem entre si a 10\% de probabilidade.

Tabela 6 - Comparação entre os teores bromatológicos médios de plantas aquáticas presentes no reservatório de Jupiá. Coletas realizadas em 8 de janeiro (verão) e 24 de julho de 2001 (inverno). Botucatu-SP, 2001

\begin{tabular}{|c|c|c|c|c|c|c|}
\hline \multirow{2}{*}{ Espécie } & \multicolumn{6}{|c|}{$\%$ na Matéria Seca } \\
\hline & $\mathrm{PB}$ & $\mathrm{EE}$ & MIN & FB & ENN & NDT \\
\hline $\begin{array}{l}\text { Egeria densa (verão) } \\
\text { Egeria densa (inverno) }\end{array}$ & $\begin{array}{l}15,8 \mathrm{a} \\
16,0 \mathrm{a}\end{array}$ & $\begin{array}{l}2,3 \mathrm{a} \\
2,6 \mathrm{a}\end{array}$ & $\begin{array}{l}13,0 \mathrm{a} \\
14,6 \mathrm{a}\end{array}$ & $\begin{array}{l}17,0 \mathrm{a} \\
15,5 \mathrm{a}\end{array}$ & $\begin{array}{l}50,6 \mathrm{a} \\
46,0 \mathrm{a}\end{array}$ & $\begin{array}{l}65,4 \mathrm{a} \\
63,3 \mathrm{a}\end{array}$ \\
\hline $\begin{array}{l}\mathrm{CV}(\%) \\
\mathrm{F}\end{array}$ & $\begin{array}{l}16,687 \\
0,83^{\text {ns }}\end{array}$ & $\begin{array}{l}27,508 \\
0,84^{\mathrm{ns}}\end{array}$ & $\begin{array}{c}18,614 \\
1,75^{\mathrm{ns}}\end{array}$ & $\begin{array}{c}21,424 \\
0,81^{\text {ns }}\end{array}$ & $\begin{array}{l}14,945 \\
1,85^{\mathrm{ns}}\end{array}$ & $\begin{array}{l}5,852 \\
1,39^{\text {ns }}\end{array}$ \\
\hline $\begin{array}{l}\text { Egeria najas (verão) } \\
\text { Egeria najas (inverno) }\end{array}$ & $\begin{array}{l}15,6 \mathrm{a} \\
16,0 \mathrm{a}\end{array}$ & $\begin{array}{l}2,3 \mathrm{a} \\
2,8 \mathrm{~b}\end{array}$ & $\begin{array}{l}15,0 \mathrm{a} \\
14,2 \mathrm{a}\end{array}$ & $\begin{array}{l}19,7 \mathrm{a} \\
17,3 \mathrm{~b}\end{array}$ & $\begin{array}{l}47,4 \mathrm{a} \\
46,6 \mathrm{a}\end{array}$ & $\begin{array}{l}63,4 \mathrm{a} \\
64,2 \mathrm{a}\end{array}$ \\
\hline $\begin{array}{l}\mathrm{CV}(\%) \\
\mathrm{F}\end{array}$ & $\begin{array}{l}10,650 \\
0,22^{\mathrm{ns}}\end{array}$ & $\begin{array}{c}17,226 \\
5,64^{*}\end{array}$ & $\begin{array}{l}15,207 \\
0,47^{\text {ns }}\end{array}$ & $\begin{array}{l}7,929 \\
9,43^{*}\end{array}$ & $\begin{array}{l}10,195 \\
0,11^{\mathrm{ns}}\end{array}$ & $\begin{array}{l}3,859 \\
0,42^{\text {ns }}\end{array}$ \\
\hline $\begin{array}{l}\text { C. demersum (verão) } \\
\text { C. demersum (inverno) }\end{array}$ & $\begin{array}{l}16,8 \mathrm{a} \\
17,4 \mathrm{a}\end{array}$ & $\begin{array}{l}1,9 \mathrm{a} \\
2,6 \mathrm{~b}\end{array}$ & $\begin{array}{l}18,6 \mathrm{a} \\
18,7 \mathrm{a}\end{array}$ & $\begin{array}{l}18,3 \mathrm{a} \\
16,1 \mathrm{~b}\end{array}$ & $\begin{array}{l}44,3 \mathrm{~b} \\
54,2 \mathrm{a}\end{array}$ & $\begin{array}{l}62,0 \mathrm{~b} \\
66,2 \mathrm{a}\end{array}$ \\
\hline $\begin{array}{l}\mathrm{CV}(\%) \\
\mathrm{F}\end{array}$ & $\begin{array}{l}15,162 \\
0,27^{\mathrm{ns}}\end{array}$ & $\begin{array}{c}20,521 \\
9,49^{*}\end{array}$ & $\begin{array}{c}16,316 \\
0,000001^{\mathrm{ns}}\end{array}$ & $\begin{array}{c}10,272 \\
6,54^{*}\end{array}$ & $\begin{array}{c}8,971 \\
18,74^{*}\end{array}$ & $\begin{array}{c}3,001 \\
21,40^{*}\end{array}$ \\
\hline
\end{tabular}

Valores seguidos de mesma letra, nas colunas, não diferem entre si a $10 \%$ de probabilidade.

E. densa foi a espécie que se mostrou intermediária em todos os parâmetros bromatológicos avaliados. Quando comparados os valores entre as épocas de amostragem (Tabela 6), nota-se que a variação sazonal não foi significativa para esta espécie. Já C. demersum apresentou maior variação sazonal nas características avaliadas, com aumento nos teores de extrato etéreo, extratos não-nitrogenados e nutrientes digestiveis totais nas plantas coletadas no inverno. 
Wetzel (1993) observou valores para os teores de proteínas, em macrófitas aquáticas submersas, em torno de $22 \%$, superior ao teor obtido em espécies emergentes e aos observados no presente estudo. Esteves (1998) relatou estudo em que comparou o valor nutritivo de algumas macrófitas tropicais e forragem, obtendo resultados médios para Elodea quatro vezes superior ao encontrado, por exemplo, em forragens (caule, folhas de canade-açúcar) e quase o dobro do encontrado em silagem de milho. Se se tomar por base o peso seco das macrófitas aquáticas, para efeito de comparação do seu valor nutritivo com plantas forrageiras, pode-se concluir que o seu teor de proteínas freqüentemente supera os encontrados em plantas utilizadas como forragem.

Segundo Esteves (1998), além do fator água presente nas estruturas das macrófitas aquáticas, a baixa palatabilidade, associada ao teor de compostos fenólicos, à presença de oxalato de cálcio e à alta concentração de sais minerais, são fatores que podem acentuar a redução de seu valor nutritivo.

As características bromatológicas da matéria seca das três espécies estudadas indicaram seu elevado potencial de uso para alimentação animal. A principal restrição refere-se ao elevado teor de umidade destas plantas, exigindo a secagem prévia para que a biomassa destas possa ser utilizada como alimento.

\section{LITERATURA CITADA}

BITAR, A. L. Fluxo de nitrogênio e seu uso por duas macrófitas (E. crassipes e $P$. stratiotes) no reservatório de Salto Grande (Americana-SP). 1998. 97 f. Dissertação (Mestrado em Ciências da Engenharia Ambiental) Universidade de São Paulo, São Carlos, 1988.

COOPLANTIO. Relação carbono/nitrogênio. 2001. Disponível em <http://www.com.br/scripts/cooplantio/pg/ printfile.exe?f=77>. Acesso em 20/11/2001.

ESTEVES, F. A. Fundamentos de Limnologia. Rio de Janeiro: Inderciência. 2.ed. 1998. 575 p.

GREENWAY, M. Nutrient content of wetland plants in constructed wetlands receiving municipal effluent in tropical Australia. Water Sci. Technol., v. 35, n. 5, p. 135-42, 1997.
HOYER, M. V. et al. Florida Freshwater Plants - A Handbook of commom aquatic plants in Florida lakes. Gainville: University of Florida, Institute of Food and Agricultural Sciences, 1996. 256 p.

MALAVOLTA, E.; VITTI, G. C.; OLIVEIRA, S. A. Avaliação do estado nutricional das plantas - Princípios e aplicações. Piracicaba: Fundação Brasileira para Pesquisa da Potassa e do Fosfato, 1989. 201 p.

MORAES, A. R. Estimativa de estoque de elementos químicos em macrófitas aquáticas do reservatório de Salto Grande (Americana-SP). 1999. 94 f. Dissertação (Mestrado em Ciências da Engenharia Ambiental) Universidade de São Paulo, São Carlos, 1999.

PINTO, M. A. T.; CAVALCANTI, C. G. B. Recuperação de lagos tropicais: Biotecnologia no controle da eutrofização em lagos tropicais - A experiência do lago Paranoá. Disponível em <www.biotecnologia.com.br/bio/ 7_h.htm>. Acesso em 12/10/2001.

PRINCIPE, C. R.; KURATANI, H.; MELONI, M. L. B. Impacto da afluência de elódeas na operação e manutenção da usina hidroelétrica Eng. Souza Dias (Jupiá) - CESP. In: CONGRESSO BRASILEIRO DA CIÊNCIA DAS PLANTAS DANINHAS, 21., 1997, Caxambu. Workshop Plantas Aquáticas... Caxambu: SBCPD, 1997. p. 5-8.

SAS INSTITUTE. SAS/STAT. User's guide: statistics. Version 6.11, Cary: 1996.

TEDESCO, M. J.; VOLKWEISS, S. J.; BOHENM, H. Análise de solo, plantas e outros materiais. Porto Alegre: UFRGs, 1985. p. 328-330.

THOMAZ, S. M.; BINI, L. M. Ecologia e manejo de macrófitas aquáticas em reservatórios. Acta Limn. Bras., v. 10, n. 1 , p. 103-116, 1998.

VALENTE, J. P. S.; PADILHA, P. M.; SILVA, A. M. M. Contribuição da cidade de Botucatu-SP com nutrientes (fósforo e nitrogênio) na eutrofização da represa de Barra Bonita. Eclét. Quím., v. 22, p. 31-48, 1997.

VELINI, E. D. Controle de plantas daninhas aquáticas. In: CONGRESSO BRASILEIRO DA CIÊNCIA DAS PLANTAS DANINHAS, 22., 2000, Foz do Iguaçu. Palestras... Foz do Iguaçu: Sociedade Brasileira da Ciência das Plantas Daninhas, 2000. p. 137-47.

WETZEL, R. G. Limnologia. 2.ed. Lisboa: Saunders College Publishing, 1993. 919 p. 